\title{
Qualidade microbiológica do leite cru comercializado informalmente no município de Barra Mansa-RJ
}

Grasielle Anacleto Dias

Graduanda em Biologia. Centro Universitário de Barra Mansa, Barra Mansa, Rio de Janeiro, Brasil.

\section{Hellen Cristina Dias da Silva}

Bióloga. Laboratório Centrolab, Volta Redonda, Rio de Janeiro, Brasil.

\section{Victor Maximiliano Reis Tebaldi}

Doutor em Ciência dos Alimentos. Centro Universitário de Barra Mansa, Rio de Janeiro, Brasil. E-mail: victormaxibio@yahoo.com.br. 


\section{Resumo}

O leite é um alimento de grande valor nutricional, alta atividade de água e elevado teor proteico, características que o tornam um excelente substrato para o desenvolvimento de microrganismos. Os tipos e números de microrganismos encontrados no leite cru podem ser usados para avaliar os níveis de contaminação existentes. $O$ trabalho visou avaliar a qualidade do leite cru em dois municípios do Sul Fluminense-RJ. Foram coletadas 10 amostras e submetidas à enumeração de microrganismos aeróbios mesófilos e psicrotróficos pelos métodos de plaqueamento em profundidade e superfície, respectivamente. A atividade proteolítica foi verificada em Ágar Leite, a partir de colônias de microrganismos psicrotróficos. A enumeração de coliformes totais e termotolerantes foi realizada pela Técnica do Número Mais Provável (NMP). A presença de coliformes fecais foi confirmada em três amostras. Uma amostra apresentou contagem de microrganismos aeróbios mesófilos acima do valor estabelecido pela legislação. Sete amostras exibiram contagem de microrganismos psicrotróficos entre $10^{3}$ e $10^{6} \mathrm{UFC} / \mathrm{mL}$. A atividade proteolítica foi confirmada em seis amostras. A qualidade do leite é influenciada diretamente pela maneira com que o mesmo é coletado, armazenado e comercializado. É necessário um controle rigoroso na higiene do animal, dos utensílios, dos ordenhadores e materiais onde o leite será armazenado.

Palavras-chave: leite cru; coliformes; microrganismos psicrotróficos; qualidade higiênico-sanitária, atividade proteolítica.

\section{Abstract}

Milk is a food of great nutritional value, high water activity and high protein content, characteristics that make it an excellent substrate for the development of microorganisms. The types and numbers of microorganisms found in raw milk can be used to assess existing levels of contamination. The objective of this study was to evaluate the quality of raw milk in two municipalities in the southern region of Rio de Janeiro. Ten samples were collected and submitted to the enumeration of aerobic mesophilic and psychrotrophic microorganisms by plating and surface plating methods, respectively. The proteolytic activity was verified in Agar Leite, from colonies of psychrotrophic microorganisms. The enumeration of total and thermotolerant coliforms was performed by the Most Likely Number Technique (NMP). The presence of fecal coliforms was confirmed in three samples. One sample presented a count of aerobic mesophilic microorganisms above the value established by the legislation. Seven samples showed a count of psychrotrophic microorganisms between $10^{3}$ and $10^{6} \mathrm{CFU} / \mathrm{mL}$. Proteolytic activity was confirmed in six samples. The quality of milk is influenced directly by the way it is collected, stored and marketed. Strict control of the hygiene of 
the animal, utensils, milking equipment and materials where the milk is to be stored is required.

Keywords: raw milk; coliforms; psychrotrophic microorganisms; contamination, hygienic-sanitary quality, proteolytic activity

\section{Introdução}

A qualidade do leite é um dos temas mais discutidos no cenário de produção leiteira. A contaminação microbiana pode geralmente ocorrer a partir de três fontes principais: interior do úbere, exterior do úbere e da superfície do equipamento de manuseio e armazenamento do leite (De SILVA et al., 2016). Por ser um alimento rico em nutrientes e, em função de suas características bioquímicas e físicas, torna-se um substrato ideal para a proliferação de microrganismos que, além da deterioração, também podem representar um risco à saúde humana (REIS et al., 2013).

O leite produzido no Brasil geralmente contém altas contagens de microrganismos aeróbios mesófilos e coliformes, o que indica falhas na higiene da produção (BUENO et al., 2004; ANGELIS et al., 2016). A qualidade microbiológica do leite cru depende basicamente das condições higiênico-sanitárias adotadas no sistema de produção, no processamento e na comercialização desse produto (SOUZA et al., 2011).

A comercialização informal de leite é uma situação que vem chamando atenção nos últimos anos, visto que a produção e a venda de leite não inspecionado têm aumentado no mesmo ritmo da produção formal, colaborando com 31,7\% do total de leite produzido no Brasil (MOLINA et al., 2015).

O consumo de leite informal no Brasil é uma prática comum, associada a fatores culturais, regionais e sociais. Apesar do perigo que esse tipo de produto pode representar para a saúde dos consumidores, fatores como praticidade, preços baixos, cultura regional, além da crença de que o produto vindo direto do produtor é mais saudável que o industrializado são as justificativas comuns para o consumo de leite in natura (BERSOT et al., 2010).

No entanto, por não passar por nenhum controle de qualidade, o leite vendido informalmente torna-se uma preocupação de saúde pública, já que pode veicular uma 
série de doenças transmitidas por alimentos (DTA), se obtido e manipulado em condições inadequadas, tornando-se um risco potencial para quem o consome diretamente ou na forma de seus derivados (MOLINA et al., 2015).

O consumo de leite cru sem qualquer passo de aquecimento prévio é geralmente desaconselhado, uma vez que a pasteurização reduz a carga microbiana (RANIERI; BOOR, 2009). Além disso, boas práticas de higiene durante o armazenamento, transporte e manuseio são de grande importância para preservar a qualidade bacteriológica original do leite pasteurizado após o tratamento térmico (SILVA et al., 2009; SOSPEDRA et al., 2009).

A contaminação do leite por microrganismos patogênicos é considerada um importante problema de saúde pública mundial (NERO et al., 2003; JAYARAO et al., 2006), especialmente em regiões em desenvolvimento, onde o leite cru é frequentemente consumido pela população, incluindo crianças e idosos. A comercialização de leite cru é ilegal no Brasil, mas os hábitos culturais e a falta de informação sobre questões de saúde pública fazem do consumo uma prática comum entre indivíduos de baixo status social (OLIVEIRA et al., 2011).

A microbiota contaminante do leite normalmente é composta por bactérias, em especial pelas psicrotróficas, que se multiplicam no leite refrigerado, enquanto que leveduras e fungos são raramente encontrados (MENEZES et al., 2014). A qualidade do leite está relacionada a problemas como alteração de sabor e odor, perda de consistência e gelatinização ao longo da vida comercial do produto, e podem estar associados à ação de enzimas de origem bacteriana que são provenientes de bactérias, principalmente do grupo das psicrotróficas. Essas enzimas apresentam a capacidade de degradar as caseínas e promover a agregação das micelas do leite (NOMBERG, 2009).

A multiplicação de microrganismos e produção de enzimas metabólicas e proteolíticas são responsáveis pela redução do tempo de vida útil do leite, que podem originar a formação de sabores indesejáveis tais como ranço e amargo (REIS, 2013).

A contagem e a determinação de mesófilos aeróbios são de grande importância, sendo sua detecção e enumeração empregadas tanto para o controle de qualidade do leite como para avaliação da eficiência das práticas de sanitização dos equipamentos e utensílios durante a produção e beneficiamento do produto (VALLIN et al., 2009; FAGAN et al., 2008). O controle microbiológico do leite e produtos lácteos se faz necessário por sua importância à saúde do consumidor (SALVADOR et al., 2012). 
Diante do exposto, este trabalho visou avaliar a qualidade microbiológica e a atividade proteolítica de bactérias psicrotróficas isoladas do leite cru comercializado informalmente no município de Barra Mansa-RJ.

\section{Material e métodos}

\section{Coleta e preparo das amostras}

As amostras foram adquiridas de produtores que comercializam leite cru diretamente à população no município de Barra Mansa, pertencente à região Sul Fluminense-RJ. Foram analisadas 10 amostras, sendo cinco comercializadas em garrafas pet e cinco provenientes de latões, coletadas diretamente nas propriedades leiteiras.

As amostras foram armazenadas em frascos estéreis devidamente identificados e acondicionadas em caixas isotérmicas contendo gelo e conduzidas ao Laboratório de Microbiologia de Alimentos do Centro Universitário de Barra Mansa.

No laboratório, alíquotas de $1 \mathrm{~mL}$ de cada unidade amostral de leite foram homogeneizadas em $9 \mathrm{~mL}$ de água peptonada 0,1\% (p/v) em agitador de tubos tipo vórtex, com posteriores diluições de três séries de três tubos para as análises de coliformes, microrganismos aeróbios mesófilos e aeróbios psicrotróficos. As análises microbiológicas foram realizadas de acordo com ICMSF (2000) e conduzidas em triplicata.

\section{Análises microbiológicas}

\section{Microrganismos aeróbios mesófilos}

Para a enumeração de microrganismos aeróbios mesófilos empregou-se a técnica de plaqueamento em profundidade (Pour Plate), selecionando três diluições e transferindo-as em alíquotas de $1 \mathrm{~mL}$ de cada uma em placas de Petri estéreis. Foi adicionado cerca de $20 \mathrm{~mL}$ de Ágar Padrão para Contagem (PCA), previamente fundido e resfriado a $44-46^{\circ} \mathrm{C}$. Em seguida o inóculo foi misturado com o meio de cultura por meio de movimentos circulares suaves em forma de "8". Após solidificação do meio as placas foram incubadas à temperatura de $35^{\circ} \mathrm{C} / 48 \mathrm{~h}$ com posterior contagem de unidades formadoras de colônias (UFC). 


\section{Microrganismos aeróbios psicrotróficos}

Para a enumeração de microrganismos aeróbios psicrotróficos, empregou-se a técnica de plaqueamento em superfície (Spread Plate) em Ágar Padrão para Contagem (PCA). Foram selecionadas três diluições adequadas das amostras e inoculado $0,1 \mathrm{~mL}$ de cada diluição na superfície das placas previamente preparadas. Com o auxílio de alça de Drigalski, o inóculo foi espalhado em toda a superfície do meio. Após, as placas foram vedadas com Parafilm $\mathrm{M}^{\circledR}$ e incubadas a $7^{\circ} \mathrm{C}$ por sete dias e posterior determinação do número de unidades formadoras de colônias (UFC).

\section{Atividade proteolítica da microbiota psicrotrófica}

Após crescimento dos microrganismos aeróbios psictrotróficos foram selecionadas 10 colônias com características morfológicas diferenciadas de cada placa de Ágar PCA das diferentes amostras, repicadas para tubos com Ágar TSA inclinado e incubadas em B.O.D a $25^{\circ} \mathrm{C} / 24 \mathrm{~h}$. As colônias isoladas foram estriadas em placas com Ágar Leite e incubadas em B.O.D a $25^{\circ} \mathrm{C} / 48 \mathrm{~h}$. Considerou-se positivo para atividade proteolítica as placas que apresentaram halo transparente ao redor das colônias.

\section{Coliformes}

\section{Teste presuntivo}

Foram retiradas assepticamente alíquotas de $1 \mathrm{~mL}$ das amostras e diluídas em 9 $\mathrm{mL}$ de água peptonada $0,1 \%$ em séries de tubos, transferindo-as em alíquotas de $1 \mathrm{~mL}$ das três diluições para séries de três tubos $\left(10^{-1}, 10^{-2}\right.$ e $\left.10^{-3}\right)$., contendo Caldo Lauril Sulfato Triptose (LST) e incubadas em estufa a $37^{\circ} \mathrm{C} / 48 \mathrm{~h}$. Foram considerados positivos os tubos com produção de gás nos tubos de Durham (presença de bolhas).

\section{Coliformes totais}

A partir de cada tubo positivo de Caldo LST, transferiu-se uma alçada para tubo de Caldo Bile Verde Brilhante (VB), previamente identificado com a diluição correspondente. Foram incubados em estufa a $37^{\circ} \mathrm{C} / 48 \mathrm{~h}$. Foram considerados positivos os tubos com produção de gás no tubo de Durham. Verificou-se, na tabela de número mais provável (NMP), o número correspondente e o resultado foi expresso em NMP de coliformes totais/mL. 


\section{Coliformes termotolerantes}

A partir de cada tubo de caldo LST positivo, transferiu-se uma alçada para um tubo de caldo EC (Caldo Escherichia coli) previamente identificado com a diluição correspondente. Incubou-se em banho-maria a $45^{\circ} \mathrm{C} / 24 \mathrm{~h}$. Foram considerados positivos os tubos com produção de gás no interior dos tubos de Durham. Verificou-se na tabela de NMP o número correspondente e expressou-se o resultado em NMP de coliformes termotolerantes ou a $45^{\circ} \mathrm{C} / \mathrm{mL}$.

\section{Escherichia coli}

A partir dos tubos positivos de caldo EC, alíquotas foram repicadas para Ágar EMB (Eosina Azul de Metileno), com auxílio de alça bacteriológica. Para cada tubo positivo em caldo $\mathrm{EC}$, correspondeu-se uma placa de ágar EMB, previamente identificada. Incubou-se em estufa a $37^{\circ} \mathrm{C} / 24 \mathrm{~h}$. Verificou-se o crescimento de colônias com características de $E$. coli, ou seja, 2 a $3 \mathrm{~mm}$ de diâmetro, com brilho metálico esverdeado ou com centro escuro abrangendo praticamente toda a colônia.

As colônias características de E. coli crescidas em EMB foram repicadas para tubos contendo Ágar TSA (Ágar Tripticase de Soja) inclinado. Procedeu-se incubação em estufa por $24 \mathrm{~h}$ a $37^{\circ} \mathrm{C}$. As culturas crescidas em Ágar TSA inclinado foram submetidas às seguintes provas bioquímicas: indol; vermelho de metila (VM); Voges Proskauer (VP); e citrato. Este grupo de prova é denominado IMVIC.

Considerou-se cultura positiva para E. coli, quando obtidos os seguintes resultados para o IMVIC:

\begin{tabular}{|l|l|l|l|l|}
\hline Indol & VM & VP & Citrato & Tipo \\
\hline+ & + & - & - & E. coli típica \\
\hline- & + & - & - & E. coli atípica \\
\hline
\end{tabular}

Fonte: Silva et al. (2010) 


\section{Resultados e Discussão}

$\mathrm{Na}$ Tabela 1, estão expressos os resultados da quantificação de microrganismos aeróbios mesófilos, aeróbios psicrotróficos, coliformes totais $\left(37^{\circ} \mathrm{C}\right)$ e coliformes termotolerantes $\left(45^{\circ} \mathrm{C}\right)$ resultantes das 10 amostras de leite cru analisadas.

Tabela 1- Quantificação de aeróbios mesófilos, psicrotróficos, coliformes totais e coliformes termotolerantes em amostras de leite cru.

\begin{tabular}{ccccc}
\hline Amostras & $\begin{array}{c}\text { Aeróbios } \\
\text { Mesófilos } \\
(\mathrm{UFC} / \mathrm{mL})\end{array}$ & $\begin{array}{c}\text { Aeróbios } \\
\text { Psicrotróficos } \\
(\mathrm{UFC} / \mathrm{mL})\end{array}$ & $\begin{array}{c}\text { Coliformes } \\
\text { Totais } \\
(\mathrm{NMP} / \mathrm{mL})\end{array}$ & $\begin{array}{c}\text { Coliformes } \\
\text { Termotolerantes } \\
(\mathrm{NMP} / \mathrm{mL})\end{array}$ \\
\hline AP & $1,4 \times 10^{3}$ & $1,2 \times 10^{6}$ & 240 & 3,6 \\
BP & $2,9 \times 10^{3}$ & $1,0 \times 10^{6}$ & $>1.100$ & 75 \\
CP & $1,3 \times 10^{2}$ & $5,6 \times 10^{5}$ & $>1.100$ & 43 \\
DP & $9,9 \times 10^{3}$ & $2,0 \times 10^{4}$ & $>1.100$ & 15 \\
EP & $8,9 \times 10^{4}$ & $4,7 \times 10^{5}$ & $>1.100$ & 460 \\
FL & $1,5 \times 10^{3}$ & 0 & 0 & 0 \\
GL & $4,0 \times 10^{2}$ & 0 & 0 & $<3,0$ \\
HL & $1,4 \times 10^{5}$ & $3,2 \times 10^{6}$ & $>1.100$ & 0 \\
IL & $1,2 \times 10^{3}$ & $1,1 \times 10^{3}$ & 0 & 0 \\
JL & $8,1 \times 10^{2}$ & 0 & 0 & 0 \\
\hline
\end{tabular}

Nota: Amostras com letras iniciais seguidas por letra "P" referem-se às amostras de leite em garrafa pet; amostras com letras iniciais seguidas por letra "L", referem-se às amostras de leite armazenadas em latão.

De acordo com as Instruções Normativas 51 e 62, ambas do Ministério da Agricultura, Pecuária e Abastecimento (MAPA) o valor máximo para expressar a contagem padrão em placas para aeróbios mesófilos é de $1,0 \times 10^{5} \mathrm{UFC} / \mathrm{mL}$ para produtores individuais nas regiões do Centro Oeste, Sudeste e Sul (BRASIL, 2002, 2011). É possível observar que apenas uma amostra (HL) encontra-se fora deste padrão.

Almeida et al. (2013) observaram que das 30 amostras de leite cru analisadas no município de Bacabal - MA, 10\% (3 amostras), estavam fora do limite padrão estabelecido para aeróbios mesófilos, esses valores assemelham-se aos encontrados no 
presente estudo. Em um estudo realizado por Molina et al. (2015) no município de Itaqui-RS, 61,9\% das amostras apresentaram valores superiores ao limite estabelecido, diferindo assim dos resultados encontrados neste estudo.

De acordo com Matsubara et al. (2011), ao desprezar os três primeiros jatos antes da ordenha há uma redução de 100\% de contaminação de aeróbios mesófilos.

As amostras analisadas neste estudo apresentaram um valor variando entre o mínimo de $1,1 \times 10^{3} \mathrm{UFC} / \mathrm{mL}$ e máximo de $3,2 \times 10^{6} \mathrm{UFC} / \mathrm{mL}$ de microrganismos aeróbios psicrotróficos nas amostras analisadas, não existindo um padrão préestabelecido para contagem total de aeróbios psicrotróficos, estes resultados corroboram com SANTOS et al. (2009).

De acordo com Martins et al. (2013), em estudo sobre a qualidade de leite, observaram a que a média geral da contagem de microrganismos psicrotróficos foi de 6,2 $\log$ UFC.mL $L^{-1}$, ressaltando que a refrigeração não inibe a multiplicação dos psicrotróficos, devendo-se evitar a contaminação do leite pela adoção de boas práticas agropecuárias, de produção ou de ordenha em todo o processo produtivo.

Das 10 amostras analisadas, sete apresentaram crescimento de microrganismos psicrotróficos. De cada uma das sete amostras foram coletadas 10 colônias e testadas quanto à atividade proteolítica. Seis amostras (AP, BP, CP, DP, EP, HL) apresentaram atividade proteolítica, de acordo com a Figura 1.

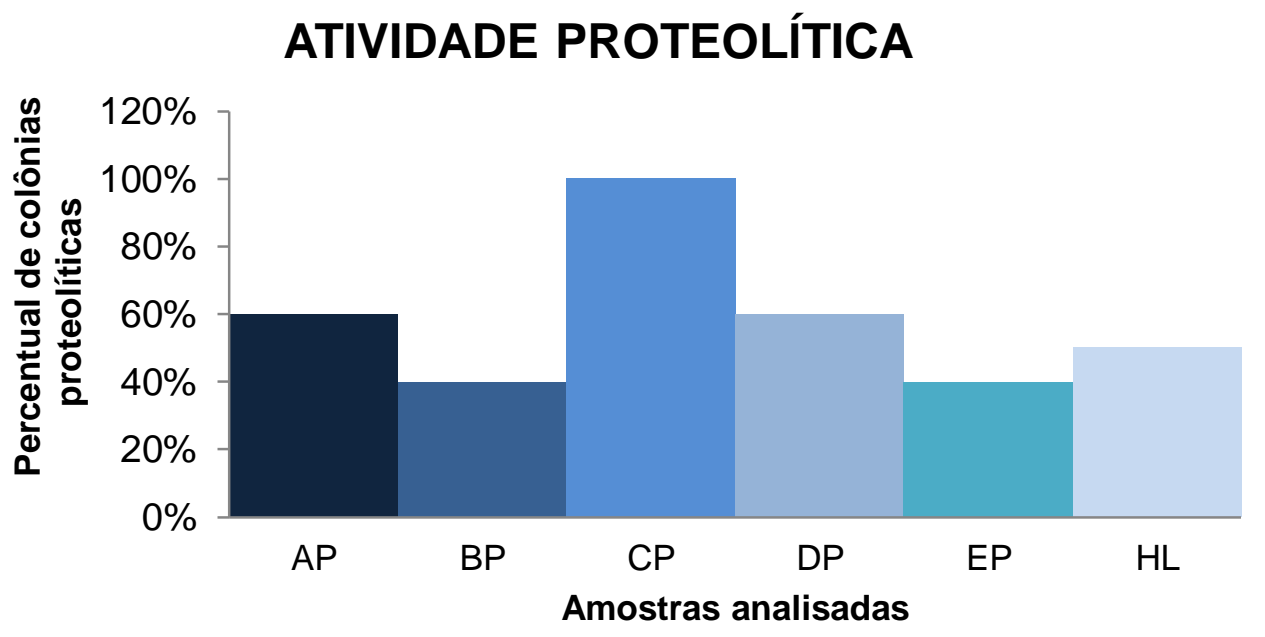

Figura 1- Atividade Proteolítica de microrganismos psicrotróficos isolados de amostras de leite cru. 
Em um estudo realizado por Tebaldi et al. (2008), dos 70 isolados de Enterobacteriaceae provenientes de amostras de leite cru, 34,28\% apresentaram atividade proteolítica, enquanto 100\% dos isolados Gram-negativos oxidase positiva pertencentes aos gêneros Pseudomonas, Alcaligenes e Burkholderia que fazem parte da biota do leite cru apresentaram atividade proteolítica.

Em estudo realizado por Nörnberg et al. (2009) com leite cru foram encontrados valores médios de atividade proteolítica variando entre 3 e $12 \mathrm{U} / \mathrm{mL}$.

De acordo com Portz et al. (2014), os psicrotróficos são produtores de enzimas proteolíticas e lipolíticas e são responsáveis por processos de deterioração do produto e perdas dos componentes sólidos do leite.

Neste estudo obteve-se um resultado elevado tanto para coliformes totais quanto para coliformes termotolerantes, a normatização não estabelece um padrão para coliformes a $35^{\circ} \mathrm{C}$ e $45^{\circ} \mathrm{C}$.

Em estudo realizado por Tebaldi et al. (2008), no qual foram analisadas 16 amostras de leite cru no Sul de Minas Gerais, 31,25\% das amostras apresentaram contagem de coliformes termotolerantes acima de $10^{3} \mathrm{NMP} \mathrm{mL}^{-1}$.

Portz et al. (2014) demonstraram que uma amostra de leite cru (10 \%) das 10 coletadas de latões e tanques de resfriamento de diferentes produtores do Distrito Federal apresentaram contagens de coliformes totais maiores que $1100 \mathrm{NMP} / \mathrm{mL}$ e todas negativas para coliformes a $45^{\circ} \mathrm{C}$.

Em um estudo realizado por Citadin et al. (2009), observou-se que 19,35\% das amostras de leite cru dentre as 31 analisadas estavam acima de $1,0 \times 10^{3} \mathrm{UFC} / \mathrm{mL}$ para coliformes totais. De acordo com Maciel (2008), valores para contagem de coliformes acima de $10^{3} \mathrm{NMP} / \mathrm{mL}$, indicam deficiências de higiene no processo de obtenção do leite.

Almeida et al. (2013) ressaltam que a presença excessiva de coliformes totais e fecais em leite in natura revela uma deficiência no controle sanitário do rebanho e higiene inadequada dos utensílios e do transporte, bem como a ausência de boas práticas de manipulação, o que leva à contaminação ambiental e fecal do leite.

Seis amostras de leite apresentaram crescimento de coliformes termotolerantes. Em três destas amostras foi confirmada a presença de $E$. coli por meio de provas bioquímicas, conforme demonstrado na Tabela 2 . 
Tabela 2 - Resultados das provas bioquímicas para confirmação da presença de Escherichia coli nas amostras analisadas.

\begin{tabular}{ll}
\hline Amostras & RESULTADO \\
\hline AP & E. Coli \\
BP & E. Coli \\
CP & E. Coli \\
DP & Ausência \\
EP & Ausência \\
GL & Ausência \\
\hline
\end{tabular}

Nota: $(\mathrm{P})$ = amostras de garrafa pet; $(\mathrm{L})=$ amostras de latão

Eckstein et al. (2011) analisaram propriedades rurais da cidade de Toledo - PR, nas quais foram coletadas 32 amostras de leite cru, sendo que 56,25\% (18) das amostras não apresentaram colônias de $E$. coli e 43,75\% (14) das amostras restantes presença de $E$. coli.

Em estudo realizado por Silva et al. (2016), no qual foram coletadas 20 amostras de leite cru refrigerado produzido nos municípios de Castro e Arapoti, região central do estado do Paraná, 14 amostras revelaram a presença de $E$. coli.

Araujo (2015), verificando a qualidade microbiológica de 6 amostras de leite cru na Zona da Mata e Agreste do Estado de Alagoas, obteve ausência de E. coli.

\section{Considerações Finais}

Apenas uma amostra apresentou contagem de microrganismos aeróbios mesófilos acima do limite estabelecido, não atendendo aos parâmetros da normativa vigente.

As análises revelaram altas contagens de microrganismos psicrotróficos em mais da metade das amostras analisadas, fornecendo indícios de práticas higiênicas deficientes ao longo da cadeia produtiva. A atividade proteolítica dos microrganismos psicrotróficos foi evidenciada em todas as amostras, tornando o produto susceptível à deterioração.

A presença de Escherichia coli foi constatada em três amostras, fornecendo desta maneira indícios de contaminação de natureza fecal do produto. 
Ressalta-se que a qualidade do leite é influenciada diretamente pela maneira que o mesmo é coletado, armazenado e comercializado. Por fim, é necessário um controle rigoroso na higiene do animal, dos utensílios, dos ordenadores e materiais onde esse leite será armazenado para comercialização.

\section{Referências}

ALMEIDA, V.M. et al. Listeria spp., coliformes, bactérias mesófilas e psicrotróficas no leite in natura e pasteurizado tipo C. Revista do Instituto Adolfo Lutz, São Paulo, v.72, n.1, p.104-109, 2013.

ANGELIS, D. et al. Qualidade do leite obtido por ordenha manual e mecanizada recebido em um laticínio do município de Argirita - MG. Veterinária Notícias, Uberlândia, v.22, n.1, p.1-6, 2016.

ARAUJO, B.F.O. Qualidade microbiológica e contagem de células somáticas de leite cru produzido na Zona da Mata e Agreste do estado de Alagoas. 2015. 49 f. Dissertação (Mestrado em Zootecnia) - Universidade Federal de Alagoas, Rio Largo, 2015.

BERSOT, L.S. et al. Raw milk trade: profile of the consumers and microbiological and physicochemical characterization of the product in Palotina-PR region. Revista do Instituto de Laticínios Cândido Tostes, Juiz de Fora, v. 65, n. 373, p. 3-8, 2010.

BRASIL. Ministério da Agricultura, Pecuária e Abastecimento. Instrução Normativa (MAPA) no 51 de 18 de setembro de 2002. Regulamento técnico de produção, identidade e qualidade de leite tipo A, tipo B, tipo $\mathrm{C}$ e cru refrigerado. Diário Oficial da República Federativa do Brasil, Brasília, 29 set. 2002, p. 13, Seção 1.

BRASIL. Ministério da Agricultura, Pecuária e Abastecimento (MAPA). Instrução Normativa no 62 de 29 de dezembro de2011. Regulamento Técnico de Produção, Identidade e Qualidade do Leite tipo A, o Regulamento Técnico de Identidade e Qualidade de Leite Cru Refrigerado, o Regulamento Técnico de Identidade e Qualidade de Leite Pasteurizado e o Regulamento Técnico da Coleta de Leite Cru Refrigerado e seu Transporte a Granel. Diário Oficial da União. Brasília, 29 de dezembro de 2011. 
BUENO, V.F.F. et al. Influência da temperatura de armazenamento e do sistema de utilização do tanqe de expansão sobre a qualidade microbiológica do leite cru. Higiene Alimentar, Campinas, São Paulo, v.18, n.124, p.62-67, 2004.

CITADIN, A.S. et al. Qualidade microbiológica de leite cru refrigerado e fatores associados. Revista Brasileira de Saúde e Produção Animal, Salvador, v.10, n.1, p.52$59,2009$.

De SILVA, S.A.S.D. et al. Microbiological quality of raw milk and effect on quality by implementing good management practices. Procedia Food Science, v.6, p.92 -96, 2016.

ECKSTEIN, I. et al. Quantificação de coliformes totais e Escherichia coli em amostras de leite cru em tanques de armazenamento. Associação Brasileira de Zootecnicistas (ABZ) - XXI Congresso Brasileiro de Zootecnia - Zootec, 2011.

FAGAN, E. P. et al. Avaliação de padrões físico- químicos e microbiológicos do leite em diferentes fases de lactação nas estações do no em granjas leiteiras no Estado do Paraná. Semina: Ciências Agrárias. Londrina, v.29; n.3; p.651-660, 2008.

\section{INTERNATIONAL COMMISSION ON MICROBIOLOGICAL} SPECIFICATION FOR FOODS. Microorganismos de los alimentos: su significado y metodos de emuneración. 2. ed. Zaragoza: Acribia, 2000. 367p.

JAYARAO, B.M. A survey of foodborne pathogens in bulk tank milk and raw milk consumption among farm families in Pennsylvania. Journal of Dairy Science, Champaign, v.89, n.7, p.2451-2458, 2006.

MARTINS, M.L. et al. Qualidade do leite cru dos tanques de expansão individuais e coletivos de um laticínio do município de Rio Pomba, MG - um estudo de caso. Revista do Instituto de Laticínios Cândido Tostes, Juiz de Fora, v.68, n.392, p.24-32, 2013.

MATSUBARA, M.T. et al. Boas práticas de ordenha para redução da contaminação microbiológica do leite no agreste. Semina: Ciências Agrárias, Londrina, v.32, n.1, p. 277-286, 2011. 
MENEZES, M.F.C. et al. Microbiota e conservação do leite. Revista Eletrônica em Gestão, Educação e Tecnologia Ambiental-REGET, Santa Maria, v. 18. Ed. Especial, p.76-89, 2014.

MOLINA, C.H.A. et al. Qualidade do leite cru comercializado em Itaqui - RS. Revista Vigilância Sanitária em Debate: Sociedade, Ciência \& Tecnologia, Rio de Janeiro, v.3, n.4, p.106-113, nov. 2015.

NERO, L.A. et al. Hábitos alimentares do consumidor de leite cru de Campo MourãoPR. Semina: Ciências Agrárias, Londrina, v.24, n.1, p.21-26, 2003.

NOMBERG, M.F.B.L. et al. Bactérias psicotróficas e atividade proteolítica no leite cru refrigerado. Acta Scientiae Veterinariae, Porto Alegre, v.37, n.2, p.157-163, 2009.

NOVAES, S.F. et al. Qualidade do leite no Brasil: um panorama de análises oficiais de monitoramento sanitário. Revista Brasileira de Ciência Veterinária, São Paulo, v.24, n.1, p.52-57, 2017.

OLIVEIRA, C.J.B. et al. Risk factors associated with selected indicators of milk quality in semiarid northeastern Brazil. Journal of Dairy Science, Champaign, v.94, n.6, p.3166-3175, 2011.

PORTZ, A.J. et al. Resíduos de antibióticos e qualidade microbiológica de leite cru e beneficiado. Revista do Instituto Adolfo Lutz, São Paulo, v.73, n.4, p.345-50, 2014.

RANIERI, M.L. et al. Bacterial ecology of high-temperature, short-time pasteurized milk processed in the United States. Journal of Dairy Science, Champaign, v.92, n.10, p.4833-4840, 2009.

REIS, K.T.M.G. et al. Qualidade Microbiológica do Leite Cru e Pasteurizado Produzido no Brasil: Revisão. UNOPAR - Científica Ciências Biológicas e da Saúde; v.15, ESP, p.411-21, 2013.

SALVADOR, F.C. et al. Avaliação da Qualidade Microbiológica do Leite Pasteurizado Comercializado em Apucarana-PR e Região. Revista Fapciência, Apucarana, v.9, n.5, p.30-41, 2012. 
SANTOS, P.A. et al. Avaliação do tempo de armazenamento sobre parâmetros de qualidade do leite cru refrigerado. Revista do Instituto de Laticínios Cândido Tostes, Juiz de Fora, v.64, n.367/368, p.35-41, 2009.

SILVA, R. et al. Pasteurized milk: efficiency of pasteurization and its microbiological conditions in Brazil. Foodborne Pathogens and Disease, New Rochelle, V.7, n.10, p.217-9, 2010.

SILVA, F.F. et al. Pesquisa de genes de virulência de Escherichia coli isoladas de leite cru refrigerado da região central do paraná. ANAIS. $1^{\circ}$ congresso de pesquisa em saúde animal e humana. Londrina-Paraná, p.240-246. 2016.

SILVA, N. et al. Manual de métodos de análise microbiológica de alimentos. São Paulo: Livraria Varela, 2010, 632p.

SOSPEDRA, I. et al. Microbial contamination of milk and dairy products from restaurants in Spain. Foodborne Pathogens and Disease, New Rochelle, v.6, n.10, p.1269-1272, 2009.

SOUZA, F. M. et al. Qualidade microbiológica do leite cru comercializado informalmente na cidade de Areia-PB. Revista Agropecuária Técnica, Areia, v.32, n.1, p.168-171, 2011.

TEBALDI V. M. R. et al. Isolamento de coliformes, estafilococos e enterococos de leite cru provenientes de tanques de refrigeração por expansão comunitários: identificação, ação lipolítica e proteolítica. Ciência e Tecnologia de Alimentos, Campinas, v.28, n.3, p.753-760, 2008.

VALLIN, M. V. et al. Melhoria da qualidade do leite a partir da implantação de boas práticas de higiene na ordenha em 19 municípios de região central do Paraná. Semina: Ciências Agrárias, Londrina, v.30; n.1; p.181 